\title{
REFLEXÕES SOBRE A POLICY MAKING E AVALIAÇÃO EM POLÍTICA PÚBLICA
}

\author{
REFLEXIONES SOBRE LA FORMULACIÓN DE POLÍTICAS Y LA EVALUACIÓN \\ DE POLÍTICAS PÚBLICAS
}

REFLECTIONS ON POLICY-MAKING AND EVALUATION IN PUBLIC POLICY

\author{
Flaviana C. V. P. M. ASSUMPÇÃO ${ }^{1}$ \\ Joana GOULART ${ }^{2}$
}

RESUMO: O presente artigo faz uma reflexão sobre a policymaking e os processos de avaliação em Política Pública sob a luz dos trabalhos escritos por Howlett et al, e os entendimentos dados, pelos autores pesquisados por eles, sobre os ciclos e subsistemas que compreendem os processos de Política Pública. Para entender sobre a tomada de decisão desses processos, foi estudado o autor Lindblom, para compreendermos quem são os atores políticos e como estes influenciam nas tomadas de decisões governamentais. Sobre a teoria da Política Pública e suas tipologias, fez necessária a leitura de T.J. Lowi e sua publicação de 1964. Para finalizar, tratamos sobre as formas de avaliação de uma Política Pública com os autores, Maria Cecília Barreira e Maria do Carmo Carvalho, no que tange as perspectivas da avaliação de políticas e programas sociais. Elizabeth Rico, sobre os processos avaliativos e Klauss Frey sobre as reflexões conceituais, dessas avaliações e suas implicações para a situação política brasileira.

PALAVRAS-CHAVE: Política Pública. Avaliação. Tomada de Decisão.

RESUMEN: Este artículo es una reflexión sobre los procedimientos de formulación de políticas y evaluación de las políticas públicas a la luz de la obra escrita por Howlett et al, y la comprensión de los datos, los autores realizaron búsquedas para ellos en los ciclos y los subsistemas que componen los procesos política pública. Para entender acerca de la toma de decisiones de estos procesos se estudió Lindblom autor, para entender quiénes son los actores políticos y cómo estos influyen en la toma de decisiones del gobierno. En la teoría de la Política Pública y sus tipologías, leyendo TJ Lowi era necesaria y su publicación en 1964. Por último, nos ocupamos de formas de evaluar una política pública de los autores, María Cecilia Barreira y Maria do Carmo en Carvalho respetar los puntos de vista de la evaluación de políticas y programas sociales. Elizabeth Rico, en relación con la evaluación y Klauss Frey procesos en las reflexiones conceptuales, las evaluaciones y sus implicaciones para la situación política brasileña.

PALABRAS CLAVE: Políticas públicas. Evaluación. Toma de decisiones

\footnotetext{
1 Doutoranda. Programa de Pós-Graduação em Educação Escolar. UNESP/Araraquara. Email: fcristine@uol.com.br

2 Doutoranda. Programa de Pós-Graduação em Educação Escolar. UNESP/Araraquara. Email: joanagoulart@ueg.br
} 
ABSTRACT: This article is a reflection on the policy making and evaluation processes in Public Policy in the light of the work written by Howlett et al, and the understanding given by the authors researched by them on the cycles and subsystems that comprise the processes of Public Policy. To understand about the decision-making of these processes, we studied the author Lindblom, to figure out who the political actors are and how they influence the government's decision-making. About the Public Policy theory and its typologies, it was necessary to read TJ Lowi and his publication in 1964. Finally, we dealt on how to evaluate a Public Policy with the authors Maria Cecilia Barreira and Maria do Carmo Carvalho regarding the perspectives of evaluation of policies and social programs, Elizabeth Rico about the evaluation processes and Klauss Frey with regard to the conceptual reflections, assessments and their implication for the Brazilian political situation.

KEYWORDS: Public Policy. Evaluation. Decision Making.

\section{Introdução}

O presente artigo faz uma reflexão sobre Política Pública, seus conceitos, objetivos, metodologias e avaliação.

O trabalho tem início com a obra Política Pública: seus ciclos e subsistemas: uma abordagem integral, de Michel Howlett; M. Ramesh; Anthony Perl (2013). A obra se baseia no recente estudo sobre subsistemas político- administrativos (policy subsystems),regimes institucionais e paradigmas políticos (policy paradigms), para entender seus elementos em sua diversidade e unificação no universo da policy-making.

Os autores utilizam o modelo do ciclo político-administrativo para analisar a policy- making pública como um processo sócio político de estágios sucessivos, que abordam a montagem da agenda, formulação, tomada de decisão, implementação e avaliação. Eles defendem uma constante repetição dos estágios desse ciclo para o aperfeiçoamento calcado nos efeitos ou impactos da política. Esta representação da policymaking resulta em uma aprendizagem política, a policy learning.

O estudo contido na obra O Processo de Decisão Política, de Charles Edward Lindblom, enfatiza a Ciência Política da década de 80 do século XX, no que tange o processo decisório, para compreender a atividade política em seu conjunto. A análise feita pela obra focalizou os aspectos da formulação política, comum a todas as etapas deste processo. O autor aborda sobre o jogo do poder, presente na política e que sempre implica na existência de regras a serem obedecidas. 
Para Lindblom, o jogo do poder e a relação dos principais jogadores, inclui as autoridades governamentais, os homens de negócios, os líderes de grupos de interesse e um pequeno número de cidadãos ativos. A grande maioria participa do jogo desempenhando papéis menores.

Além dos autores citados, foi consultada a obra de Theodore Lowi denominada American Bussiness, PublicPolicy, Case Studies and Political Theory, que aborda estudo de caso para Ciência Política ocorrido na década de 30, do século XX, nos EUA. A obra faz uma análise das relações políticas em um contexto único, relacionada a negócios, atitudes, estratégias de comunicação e relações comerciais na política. $\mathrm{O}$ autor apresenta três categorias principais de políticas públicas: distributivas, regulatórias e redistributivas. Essas categorias de política constituem arenas de poder. Cada arena terá sua própria característica no que tange à estrutura política, ao processo político, às elites e às relações de grupo.

Políticas Públicas requerem uma análise para compreendermos suas implicações e conceitos. $\mathrm{O}$ autor estudado, que direciona esse aspecto no artigo é Klaus Frey e sua obra Análise de políticas públicas: algumas reflexões conceituais e suas implicações para a situação brasileira.

Para Frey as políticas públicas ganham espaço e importância dentro da Ciência Política e Administrativa. Surgem em países desenvolvidos com regimes democráticos estáveis e consolidados. No seu trabalho, o autor estuda as Políticas Públicas em suas três dimensões: Polity-Instituições Políticas; Politics-Processo Político e Policy- Conteúdos da Política.

Para entendermos sobre a Efetividade, Eficácia e Eficiência de uma Política Pública, a obra Avaliação de políticas sociais: uma questão em debate, organizada por Elizabeth M. Ricco, no capítulo Tendências no estudo sobre avaliação, de Marta T.S. Arretche, foram consultados.

Arretche, em sua obra escreve que a avaliação em política pública pode ressaltar o caráter político do processo decisório, além dos valores e critérios nela identificáveis. A avaliação política nesta perspectiva prescinde do exame da operacionalidade concreta ou da implementação do programa sob análise. Ela examina os pressupostos e fundamentos políticos de um determinado curso de ação pública, independentemente de sua engenharia institucional e de seus resultados prováveis. 
Finalizando essa reflexão, a obra Tendências e perspectivas na avaliação de políticas e programas sociais, organizado por Maria Cecília Barreira, demonstra que a avaliação em política não está voltada para a análise de sua natureza, dimensão ou abrangência, mas destina-se a compreender e explicar os motivos, razões ou argumentos que levaram os governos a adotar uma política pública, em detrimento de outra.

\section{O que é política pública?}

Por Política Pública, entende-se o conjunto de ações e decisões dos governos, voltados para a solução (ou não) de problemas sociais.

Para compreendermos como uma Política Pública é efetivada, é necessário entender sua conjectura teórica e formativa.

Para Dye (1972 apud HOWLETT et al, 2013, p. 6), Política Pública é "tudo o que um governo decide fazer ou deixar de fazer". Definição que confere o mesmo tratamento de Política Pública a todo e qualquer comportamento governamental.

Essa política possui méritos que especifica que o agente primário da policy-making é uma determinação consciente de um governo, que pode gerar efeitos não intencionados ou intencionados. Esta envolve uma decisão fundamental por parte dos governos, a qual é tomada por políticos eleitos e funcionários oficiais (HOWLETT, et al, 2013).

Estes pontos, descritos por Dye, permitem estudar a Política Pública como um processo aplicado de resolução de problemas. Sua definição traz a ideia de decisões governamentais conscientes e deliberadas.Howlett, et al (2013), escrevem que a teoria da Política Pública focaliza três dimensões: os atores, as instituições e as ideias.

Os estudos contemporâneos da Política Pública certamente mantêm a vitalidade intelectual daqueles que deram origem à abordagem. Seu foco não está tanto na estrutura dos governos ou no comportamento dos atores políticos ou naquilo que os governos deveriam ou têm que fazer, mas naquilo que os governos de fato fazem. Essa abordagem põe o foco no desenvolvimento de generalizações e leis sobre políticas públicas e policy-making pública, ou no modo como seus autores originais a denominaram, ciência política (policyscience). (HOWLETT et al, 2013, p.22)

Os autores utilizam o modelo do ciclo político administrativo, que concebe a policy-making como um processo sócio político e técnico político de estágios sucessivos,

3 Esses três universos encontram-se na poliçysubsystems (político administrativo), policyparadigms (paradigmas políticos) e policymaking diversidade e unificação). 
como: montagem da agenda, formulação, tomada de decisão, implementação e avaliação da Política Pública.

Quadro 1: Etapas do processo

\begin{tabular}{|c|c|}
\hline Agenda & $\begin{array}{c}\text { O problema chega à atenção dos governos } \\
\text { Formulação }\end{array}$ \\
$\begin{array}{c}\text { Propostas formuladas para atender o } \\
\text { problema identificado. }\end{array}$ \\
\hline decisão & $\begin{array}{c}\text { Escolha da melhor proposta, dentre as } \\
\text { formuladas }\end{array}$ \\
\hline Implementação & Execução da Política Pública \\
\hline Avaliação da & Monitoramento dos resultados. \\
Política Pública & \\
\hline
\end{tabular}

Fonte: Howlett et al (2013)

Existe a defesa dos autores, sobre uma constante observação dos estágios e seus ciclos para aperfeiçoar os impactos gerados pela implementação da política.

Esse processo de compatibilização possui duas dimensões, a técnica que prevê a identificação entre a melhor relação entre objetivos e instrumentos e a política, que pode apresentar divergências entre os atores e o processo de implementação da Política Pública.

A forma como Dye determina os pontos da policy-making, permite estudar a Política Pública como um processo de resolução de problemas resultante de uma oportunidade de escolha.

Jenkins (1978 apud HOWLETT et al, 2013, p. 8) amplia a definição de Dye sobre Política Pública, ao destacar a ideia de que a capacidade do governo para implementar suas decisões é um componente importante desta forma de política. O entendimento das ações de um governo, requer uma compreensão detalhada das oportunidades e limites proporcionados pelos acordos, tratados e convenções internacionais.

Para compreender a Política Pública, é necessário conhecer os processos e implicações metodológicas que cercam seu estudo. Para isso, é preciso considerar não apenas os registros oficiais para cada tomada de decisão governamental, mas todo o processo.

Os modelos e técnicas de referências para tais investigações se dividem em dois grupos: 
A- Positivistas, que buscam realizar uma análise das metas, objetivos e consequências de uma política utilizando metodologia padrão das Ciências Sociais para coleta e análise de dados;

B- Pós positivistas que adotam técnicas interpretativas, subjetivas para ajudá-los a discernir e criticar os alvos, propósitos e ações do governo.

Na perspectiva positivista, a análise das consequências da adoção de uma Política Pública é realizada de forma objetiva confrontando metas e resultados, além de utilizar técnicas quantitativas, análises da relação de custo/benefícios e abordagem dos riscos. O pós positivista se utiliza de técnicas interpretativas, seu objeto de exame abrange as causas, os propósitos, as ações do governo e os processos que levaram a adoção da referida Política Pública.

Os pospositivistas [...] não se opõem à objetividade e à análise empírica em si. Pelo contrário, acreditam que a análise empírica (positivista) precisa ser combinada com a análise normativa (pospositivista), porque as duas são inseparáveis, uma posição que foi, de fato, explicitamente defendida por fundadores das policyscienses, como Harold Lasswell. (HOWLETT et al, 2013, p.32)

Lasswell, fundamenta a policyscience em três pontos, conforme Howlett et al (2013):

A- Multidisciplinar que abandona o estudo das instituições e estruturas políticas para trabalhar com as conclusões emanadas pela Sociologia, Economia, Direito e Política.

B- Solução de problemas, que afasta o saber acadêmico dos clássicos da política e passa a olhar para a resolução de problemas do mundo real.

C- Normativo, onde os analistas políticos comparam as opções e apontam alternativas. Dentro desse ciclo, existe ainda, o ciclo da Política Pública e um modelo aplicado para a resolução de problemas.

\section{Ciclo político administrativo}

A policy-making foi pensada como um conjunto de estágios inter-relacionados por Lasswell(1956).Nesse processo, denominado ciclo político administrativo, os temas políticos e as deliberações fluem de modo sequencial, desde os problemas até os produtos. 
Esse modelo concebe a policy- making em termos pragmáticos. Destaca a contínua relação entre teoria e prática, resultando em um processo de tentativa e erro para escolher uma política, monitorar seus resultados e ajustar suas ações aos próximos estágios.

Lasswell dividiu o ciclo político administrativo em sete estágios: informação; promoção; prescrição; invocação; aplicação; término e avaliação.

Entretanto, analisando o ciclo político pensado por Lasswell, Howlett et al, (2013) encontra duas falhas como: 1- A tomada de decisões ocorre no interior do governo, desconsiderando as influências externas sobre o Estado; 2- Situa a apreciação da política somente após o seu término.

Brewer (1974) e Howlett et al (2013) abordam um modelo mais simples de ciclo político administrativo dividido em seis estágios: invenção/ iniciação; estimativas, seleção, implementação, avaliação e término.

Tal modelo representou um aperfeiçoamento, pois ultrapassou a fronteira do governo na exploração de como os problemas são reconhecidos e introduziu a noção de processo político como um ciclo em constante movimento (HOWLETT et al, 2013).

Esse modelo desenvolvido por Brewer (Howlett et al, 2013) apresenta certa vantagem e desvantagem. A vantagem está na possibilidade de compreensão mais ampla do processo devido à sua desagregação em estágios. A desvantagem, o modelo pode ser mal interpretado, sugerindo que a policy making segue uma progressão linear.

Para Lindblom (1984), em O Processo de Decisão Política, o processo decisório na política, no mundo liberal democrático, abarca duas questões fundamentais que são: como tornar as políticas mais eficazes na solução de problemas e como tornar tal processo sensível ao controle popular.

Sobre a primeira questão, a maioria das pessoas acredita no aumento da informação, da reflexão e da análise no processo de decisão política.

Entretanto, há um conflito em relação a esse processo de um lado, defendem a discussão das ideias para que o processo decisório, seja mais democrático e deliberativo; de outro, argumentam que essa discussão pode gerar conflitos, por isso preferem que a política seja mais científica.

Se o processo decisório é direcionado pela análise científica, a escolha da política ocorre por meio de uma investigação. Se esse processo é direcionado pela política, tal escolha ocorre pela ação. Nessa forma de solução de problemas, toda ação é considerada uma interação. 
Desta forma, persiste o conflito entre a razão, a análise e a ciência de um lado, e a política e a democracia de outro. Lindblom (1981, p.14) prevê que a "análise e a 'política' se complementem mutuamente "no processo de tomada de decisão.

Para o autor, quando o processo decisório ocorre por meio da interação, ele pode alcançar resultados maiores do que quando ocorre pela análise, pois a interação permite conciliar a diferença; neste caso, a análise, atua como um método de controle.

No que tange a análise para aperfeiçoar o processo decisório, encontra-se em Lindblom, duas vertentes, a Visão Científica que defende a elevação do nível analítico no processo decisório. As etapas desse processo se assemelham às fases do método científico. A política é o resultado de um processo intelectual e não político; e o Ideal Estratégico, que defende a prioridade da interação no processo decisório e a simplificação da análise de todas as formas possíveis (método de tentativa e erro).

Entretanto, essa análise não é capaz de responder aos diferentes problemas, interesses, poderes existentes no processo decisório, os quais somente se resolvem a partir da discussão política.

O papel da análise em tal processo é limitado por suas deficiências, que são: ela é falível e não pode resolver os conflitos sobre valores e interesses; Uma análise exige grande dispêndio de tempo e custos além de não poder determinar de modo conclusivo, quais problemas precisam ser abordados.

Mediante essas deficiências, o autor propõe a introdução, preferencialmente, da política no processo decisório e a consideração da análise, a partir de uma perspectiva diferente, ou seja, como parcial.

Mas, para entender um processo de tomada de decisão política é necessária uma análise detalhada, dessa forma como isso ocorre?

A análise se caracteriza como parcial, partidária ou sectária e pode ser empregada como um instrumento de controle no processo decisório. Esta análise é parte da política; diferente da análise anterior que é uma alternativa para a política (LINDBLOM, 1981, p. 29).

Os processos de controle por interação ocorrem em um jogo do poder, no qual as "pessoas se influenciam reciprocamente, resultando em um conjunto de inter-relações mais complexas do que o termo genérico "política"' (LINDBLOM, 1981, p. 39).

Os formuladores de políticas e os cidadãos comuns são elementos fundamentais desse jogo do poder. Além destes, tal jogo ainda possui uma parcela de participantes 
intermediária, que terão um desempenho variável de sistema para sistema. O jogo do poder sempre implica na existência de regras a serem obedecidas. Há grupos na sociedade que exercem maior poder que outros.

Nesse jogo, controlar significa aprisionar, intimidar, trocar favores, ganhar aliados ou silenciar críticas. Os métodos de controle funcionam mediante a promessa de prêmios e a ameaça de penalidades.

O sistema democrático passa por esse jogo e apresenta métodos de controle que são vão desde a persuasão e a análise parcial, que são métodos calcados em ganhos e perdas. Passa pela ameaça, faculdade creditada a autoridades governamentais; observa o intercâmbio, que é a troca de vantagens entre as partes envolvidas, que serão beneficiadas, e pôr fim a autoridade, associada a obediência de indivíduos às regras impostas por outro, por aceitar como válida suas ordens.

No sistema democrático, esse jogo do poder inclui traços adicionais. Tal sistema é caracterizado por regras como: a livre manifestação de ideias, a faculdade de reunião dos cidadãos e escolha de um representante, a ampla elegibilidade e a autoridade dos eleitos sobre outros funcionários.

Essas regras afetam o jogo do poder no processo decisório, pois contribuem para dispersar o controle exercido sobre tal processo e limitar as disputas entre os líderes políticos a formas brandas, o que torna a busca de votos vital. O processo decisório está nas mãos de uma elite eleita e de autoridades nomeadas.

Para Lindblom (1981) os atos administrativos que fazem ou alteram políticas ao implementá-las, se constituem como parte integrante de seu processo de construção. Diante da impossibilidade de elaborar um texto legal que cubra todas as contingências, os responsáveis pela administração determinam os elementos das concepções que tal texto apenas esboça. Nestes casos, a burocracia fica com a maior parte da autoridade no processo de decisão política. Ao programarem as políticas, os burocratas (homens de negócios) se tornam participantes do processo decisório. Estes atores usam na política os métodos de controle já expostos.

\section{Os homens de negócios no processo de decisão política.}

Para Lindblom (1981) além dos funcionários do governo, o processo decisório abarca a participação de um segundo grupo elitista de servidores públicos - os homens de negócios, que desempenham funções públicas importantes, embora não sejam 
governamentais. O seu não cumprimento, ou mau desempenho, pode derrubar o governo e levá-lo a uma recessão.

Diante dessa realidade, estes homens ocupam uma posição privilegiada no jogo do poder que condiciona a decisão política, permitindo às empresas o controle sobre esse processo e as políticas governamentais. O número de políticas que o meio empresarial pode influenciar é ilimitado. Os homens de negócios exercem controle sobre o governo por meio da persuasão.

Pela persuasão, os homens de negócios e as autoridades governamentais promovem uma confusão entre os termos democracia, sistema de empresa livre e nação, denotando uma histórica ligação entre ambas.

Lindblom (1981) explica que as decisões políticas passam pelos interesses dos grupos formados pelos homens de negócios.

Os grupos de interesse representam o principal método de exercer influência no processo de decisão política. Os líderes desses grupos integram uma terceira parcela da elite que constitui tal processo. Estes não desempenham com muita frequência as funções que caracterizam o ser humano como prevê a Teoria do Grupo. A participação nestes grupos ocorre normalmente a partir de uma experiência superficial e são concebíveis como indispensáveis nos sistemas democráticos, pois representam uma manifestação do livre pensamento, do direito de petição e assembleia.

Esses grupos não exercem a mesma influência no processo decisório; tudo dependerá das regras do jogo.

O autor salienta que pesquisas realizadas nos EUA, na década de 80 do século XX, apontaram que a participação dos indivíduos na política estava ligada à sua renda e status, e à questões maiores como a desigualdade na busca de informações políticas e a desigualdade educacional.

A pessoa só tem participação política se aprenderam a aceitar sua importância, se aprenderam a atuar como cidadãos, se foram doutrinadas nas aspirações e expectativas que estimulam ao invés de paralisar, se aprenderam a se considerar membros de uma comunidade política (LINDBLOM, 1981, p. 89).

Diante da desigualdade política, escrita por Lindblom (1981), pode-se pensar que o voto se distribui igualmente nos sistemas democráticos; mas não é bem assim. Os eleitores votam em favor de candidatos e não de políticas. 
O controle exercido pelo eleitorado é limitado, visto que este não tem conhecimento de seu candidato que no período eleitoral, não se define a respeito de temas pontuais ligados a Política Pública, por não terem conhecimento sobre o mesmo. A discrepância entre candidatos e eleitores aumenta, após a eleição.

Essa discrepância tem os partidos políticos como maiores contribuintes, visto que diminui os obstáculos entre eleitores e candidatos, mantendo uma aproximação entre eles. Os partidos auxiliam os candidatos na escolha das políticas que a maioria dos eleitores prefere, fazendo com que estes (eleitores) acreditem que estão no controle no processo de decisão política.

Uma relação política é determinada pelo tipo de política em jogo, de modo que, para todo tipo de política, é provável que exista um tipo distinto de relação política. (LOWI, 1964, p. 688).

\section{Categorias de políticas públicas}

São apresentadas três categorias principais de Políticas Públicas: as políticas distributivas, as políticas regulatórias e as políticas redistributivas.

Essas categorias de política constituem as "arenas de poder". Cada arena terá suas próprias características no que tange à estrutura política, ao processo político, às elites e às relações de grupo (LOWI, 1964, p. 689-690).

Políticas Distributivas, são caracterizadas pela facilidade com que podem ser desagregadas em pequenas unidades; cada unidade é mais ou menos isolada das outras e de qualquer regra geral. Tais políticas beneficiam clientes específicos, chamados favorecidos, por isso são constituídas de decisões individualizadas. Nestas políticas o cliente favorecido e o desfavorecido, não se enfrentam diretamente. Por serem facilmente multiplicáveis, elas conseguem atender interesses diferentes simultaneamente. Dessa forma, predomina na arena distributiva uma relação mais estável caracterizada por poucos conflitos, devido a não interferência mútua entre os interesses que se dirigem aos tomadores de decisão (LOWI, 1964).

Políticas Regulatórias, não são passíveis da desagregação; as decisões estão relacionadas a padrões legais amplos, a decisões setoriais, e devem ser tomadas mediante a aplicação de uma regra geral. Tais políticas envolvem uma escolha direta entre favorecidos e desfavorecidos, estabelecendo com clareza cada um desses atores. Elas diferem, 
portanto, das políticas distributivas, que definem apenas os clientes favorecidos. As políticas regulatórias tendem a gerar relações conflituosas. Atores afetados por tal política podem formar coalizões e lutar contra os atores favorecidos com interesses diferentes dos seus. Essa arena é caracterizada pelo pluralismo. Por tratar de assuntos de natureza comum ou setoriais, os interesses se tangenciam, configurando tal arena como produto de conflitos (LOWI, 1964).

Políticas Redistributivas são comparadas à política regulatória, por exercer impacto sobre categorias ainda mais amplas de indivíduos, como as classes sociais. Essa política não favorece um indivíduo, mas um grupo maior de pessoas que apresenta consequências sociais. Tais políticas, geralmente afetam a alocação da propriedade, da riqueza ou da renda. A arena redistributiva é mais coesa, com interesses compartilhados. Ex. a "luta pelo Estado de Bem-Estar Social” nos Estados Unidos na década de 1930 (LOWI, 1964)

Essas três categorias de políticas públicas podem oscilar em torno de uma questão principal em um espaço temporal relativamente curto. Ex. Imposto de renda.

Entretanto, a de se pensar, mas como avaliar se as Políticas Públicas estão de fato atendendo os interesses daqueles que a recebem?

Frey (1999) fez uma análise sobre como proceder a um processo de avaliação de Política Pública.

A avaliação em Política Pública pode ressaltar qual o caráter político do processo decisório que implicou na adoção de uma dada política, e quais os valores e critérios nela identificáveis. A avaliação política nesta perspectiva prescinde do exame da operacionalidade concreta ou da implementação do programa sob análise. Ela examina os pressupostos e fundamentos políticos de um determinado curso de ação pública, independentemente de sua engenharia institucional e de seus resultados prováveis.

Segundo Frey (1999), as Políticas Públicas ganham espaço e importância dentro da ciência política e administrativa, elas surgem em países desenvolvidos com regimes democráticos estáveis e consolidados. É através de seu processo que ocorre a redução das desigualdades além da construção de uma política democrática do Estado desenvolvido e estável.

Desta forma, existem abordagens para entender a Política Pública no âmbito da Ciência Política. São elas: 
A- Questionamento Clássico: que tem por base os pressupostos de Platão e Aristóteles, no que diz respeito ao que é bom para garantir e proteger a felicidade dos cidadãos e da sociedade;

B- Questionamento Político: que analisa as forças políticas necessárias para uma tomada de decisão. É voltada a campos específicos como políticas econômicas, financeiras, tecnológicas, sociais, educacionais, de saúde, habitação e ambiental.

Estas formas de questionamentos passam por metodologias de estudos que analisam três dimensões políticas:

A- Polity: Instituição Política, refere-se aos conteúdos concretos dos programas políticos, aos problemas técnicos e ao conteúdo material das decisões políticas. Frey (1999) escreve que na polity é necessária uma análise cuidadosa frente às condições peculiares das sociedades em desenvolvimento, como é o caso do Brasil.

B- Politics: Processo Político de caráter conflituoso que impõe objetivos aos conteúdos e decisões de distribuição de determinada Política Pública.

C- Policy: Conteúdos Políticos, delineados pelo sistema jurídico e a estrutura institucional do sistema político- administrativo ligado aos sistemas de governo, eleitoral e propaganda política.

Para o autor é necessário observar que sistemas políticos em transformação e com instituições não consolidadas, como ocorrem em países da América Latina, Leste Europeu e países do Terceiro Mundo, necessitam de controle institucional em suas estruturas, devido a fragilidade de seus sistemas políticos.

Tal afirmação leva em conta a instabilidade das estruturas institucionais e dos padrões políticos administrativos de países em desenvolvimento, com democracias do tipo delegativo, como é o caso do Brasil. Percebe-se que a análise de Políticas Públicas não pode dispensar uma análise dos fatores polity e politics com ênfase na sua dimensão processual, para poder assim fazer justiça a realidade empírica bastante complexa.

Sendo assim, é recomendável fazer uma diferenciação horizontal da política nas dimensões policy, politics e polity e realizar também uma verticalização tendo como base a política federal, estadual e municipal no âmbito da política setorial de programas e projetos. 


\section{Avaliação de política pública.}

Para Arretche (2001) avaliação em Política Pública prescinde de um exame sobre a operacionalidade concreta da implementação do programa a ser analisado. Esta avaliação examina os pressupostos e fundamentos políticos da ação pública, independentemente de sua engenharia institucional e de seus resultados.

Para entender o X e Y das Políticas Públicas, é necessário compreender três princípios básicos,

A- Efetividade: é precisamente na avaliação de efetividade que a distinção entre avaliação e análise se torna mais clara e necessária, devido à necessidade de demonstrar que os resultados encontrados na realidade social estão causalmente relacionados àquela política particular. E, adicionalmente, da necessidade de distinguir entre os produtos de uma política e seus resultados. Exemplo: Lei 6.259 de 30-10-1975 e Decreto 78.231 de 3012-76, que deu ênfase às atividades permanentes de vacinação, à luz da avaliação de Políticas Públicas, realizadas a partir de campanhas em massa, contra a varíola na década de 70 do século XX. Entretanto, nas avaliações de efetividade, a maior dificuldade metodológica não consiste em distinguir produtos de resultados. De fato, a principal dificuldade metodológica consiste precisamente em demonstrar que os resultados encontrados (sejam eles no sentido do sucesso ou do fracasso) estão causalmente relacionados aos produtos oferecidos por uma dada política sob análise. Por esta razão, estudos confiáveis sobre efetividade dos programas são muito difíceis, e mesmo raros.

B- Eficácia: a avaliação de eficácia é a mais aplicada nas correntes de Políticas Públicas. Isto porque ela é a mais factível e menos custosa de ser realizada. Na verdade, o avaliador estabelece uma equação entre metas anunciadas por um programa e, com base nas informações disponíveis, as relaciona às metas alcançadas e, deste modo, conclui pelo sucesso ou fracasso da política. Neste tipo de avaliação, a maior dificuldade consiste na obtenção e confiabilidade das informações obtidas. Exemplo: política monetária, definida pela Curva de Phillips ${ }^{4}$, onde se leva em consideração a inflação e metas estipuladas pelo governo, inflação esperada, taxa de desemprego, taxa natural de desemprego e elemento aleatório.

\footnotetext{
${ }^{4}$ Uma das relações centrais para a análise macroeconômica moderna é a "Curva de Phillips", ou o trade-off entre inflação e desemprego. Schwartzman (2006).
} 
C- Eficiência: a avaliação da eficiência é possivelmente hoje a mais necessária e a mais urgente de ser desenvolvida. E, na verdade, tem sido feito um grande esforço de sofisticação dos métodos de avaliação de eficiência nos anos mais recentes. Isto tem ocorrido sob o impulso de vários fatores. Em primeiro lugar, porque a escassez de recursos públicos exige maior racionalização do gasto. Na verdade, sob o impacto da crise físcal do Estado, medidas e programas de racionalização da ação pública têm buscado aumentar o volume de recursos efetivamente disponíveis sem aumentar o volume de arrecadação e/ou sem aumentar rubricas de gasto. Em segundo lugar, os estudos de avaliação da eficiência tornam-se cada vez mais necessários no Brasil porque, paralelamente à escassez de recursos públicos, os universos populacionais a serem cobertos pelos programas sociais são de grandes proporções.

Para Barreira et al (2001) a avaliação política não está voltada para análise da natureza, dimensão ou abrangência de uma política social, mas destinasse a compreender e explicar os motivos, razões ou argumentos que levam (ou levaram) os governos a adotar uma política pública, em detrimento de outra.

A avaliação política se dedica a explicar o processo decisório e os fundamentos políticos da existência de uma política social, constituindo um objeto de estudo privilegiado da ciência política. Esse tipo de avaliação, assim, pouco se preocupa em compreender o escopo ou funções, ou mesmo a composição de uma dada política social.

\section{Considerações finais}

O presente artigo apresentou uma pequena reflexão sobre Política Pública, seus conceitos, critérios, metodologias, aplicações e avaliação. Ao longo do texto, observa-se, que mesmo autores estadunidenses da segunda metade do século XX, como autores brasileiros, expõe as fragilidades de se avaliar uma política pública devido os atores nela envolvidos.

Jogos de poder, regras de jogo, homens de poder e poder de decisão, são palavras encontradas nos textos estudados. No texto de Frey, fica claro como esse jogo de poder acontece no Brasil, onde, devido à forma como os partidos políticos orientam seus candidatos sobre o que, como e onde falar com os eleitores, aumenta a desigualdade social, já existente. 
Sobre os modos de se avaliar uma política pública, evidencia-se a necessidade de se obter métodos mais eficazes e objetivos que possam mostrar como de fato recurso financeiro tem sido utilizado pelos governos. Os autores, que respaldam o texto, esclarecem como surge a policy-making pública, desde a montagem da agenda, formulação, tomada de decisão, implementação e avaliação, dos programas políticos. Também esclarecem quem são os atores que receberam a política bem como seus formuladores.

Em época de eleição, compreender as desigualdades políticas, auxilia a perceber como os votos se distribuem e como os eleitores votam em favor de candidatos e não de políticas. O trabalho, pode auxiliar, a entender melhor o sistema político partidário, a importância de formular agendas públicas, sociais, de financiamento e de avaliação para compreender se a política pública cumpriu seu papel de efetividade, eficiência e eficácia.

\section{Referências}

BARREIRA, Maria Cecília R. Nobre; CARVALHO, Maria do Carmo Brantde (Orgs.). Tendências e perspectivas na avaliação de políticas e programas sociais. São Paulo: IEE/PUC-SP,2001.

FREY, Klaus. Análise de políticas públicas: algumas reflexões conceituais e suas implicações para a situação brasileira. Cadernos de Pesquisa, Programa de PósGraduação em Sociologia Política, nº18. Florianópolis. UFSC,1999.

HOWlett, M.; RAMESH, M.; PERL, A. Política Pública: seus ciclos e subsistemas. Rio de Janeiro. Ed. Elsevies, 2013. Cap.I.

HOWlett, M.; RAMESH, M.; PERL, A. Política Pública: seus ciclos e subsistemas. Rio de Janeiro. Ed. Elsevies, 2013. Resenha de: MOTA, C. R. S. Disponível em: $<$ https://periodicos.ufpel.edu.br/ojs2/index.php/pensamentoplural/article/download/5696/4 265>. Acesso em: 24 out. 2016.

\section{LINDBLOM, C. E. O processo de decisão política. Brasília. EdUnB,1981.}

LOWI, T. J. American Business, public policy, case studies and political theory. In: World Politics. XVI, USA, 1964.

LOWI, T. J. American Business, public policy, case studies and political theory. In: World Politics. XVI, USA, 1964. Resenha de: MEDEIROS, O. L. Tipos de políticas públicas. Disponível em: <https://pt.scribd.com/doc/97377630/Tipologia-de-Lowi-parapoliticas-publicas>. Acesso em: 24 abr. 2016. 
RICO, Elizabeth Melo (org.). Avaliação de Políticas Sociais. São Paulo: Cortez Editora, 1998.

SEBRAE. Políticas Públicas: conceitos e práticas/ supervisão Brenner Lopes e Jefferson Ney Amaral; coordenação de Ricardo W. Caldas. Belo Horizonte, 2008.

SCHWARTZMAN, Felipe Farah. Estimativa de Curva de Phillips para o Brasil com preços desagregados. Econ. Apl. vol.10 no.1 Ribeirão Preto jan./mar. 2006. Disponível em: <http://www.scielo.br/scielo.php?script=sci_arttext\&pid=S1413-80502006000 1000 08>. Acesso em: 26 abr. 2016.

\section{Como referenciar este artigo}

ASSUMPÇÃO, Flaviana C.V.P.M. e GOULART, Joana. Reflexões sobre a policy making e avaliação em política pública. Revista on line de Política e Gestão Educacional, Araraquara, v.21, n.01, p. 47-63, 2017. Disponível em: <http://dx.doi.org/10.22633/rpge.v21.n.1.2017.9987>. ISSN: 1519-9029.

Submetido em: 16/12/2016

Aprovado em: 30/03/2017 